\title{
UNUSUAL CASE PRESENTATION: SPONTANEOUS RUPTURE OF BICORNUATE UTERUS WITH 24 WEEKS OF PREGNANCY
}

Vijayalakshmi B ${ }^{1}$, Chandana $\mathrm{N}^{2}$

\section{HOW TO CITE THIS ARTICLE:}

Vijayalakshmi B, Chandana N. "Unusual case presentation: Spontaneous Rupture of Bicornuate Uterus with 24 weeks of pregnancy". Journal of Evolution of Medical and Dental Sciences 2014; Vol. 3, Issue 07, February 17; Page: 1709-1712, DOI: $10.14260 /$ jemds/2014/2046

INTRODUCTION: Gestation in one horn of bicornuate uterus is a rare form of pregnancy that poses a diagnostic and therapeutic challenge. Abnormal fusion of the mullerian ducts during embryonic life results in a variety of congenital uterine malformations. Uterine malformations are estimated in 3-5\% of general population and of which $15-25 \%$ have problems with fertility. The incidence of miscarriage, poor fetal growth, mal presentations and ectopic pregnancies is also more. More than $50 \%$ of women with malformed uterus stay asymptomatic ${ }^{1 .}$

KEYWORDS: Bicornuate Uterus, Cornual pregnancy, uterine rupture, mullerian fusion defects, pregnancy complications.

Failure of mullerian duct fusion may lead to variety of uterine defects. They are

1) Uterus didelphys -Uterus may be duplicated with two body and two cervices.

2) Septate Uterus -There may be a complete septum through the septum making two uterine cavities and two cervices.

3) Bicornuate uterus -There may be two separate uterine bodies with one cervix.

4) Unicornuate uterus -One mullerian duct may fail to develop leaving one uterine tube and half of the body of the uterus.

\begin{tabular}{|l|c|}
\hline Infertility & $4 \%$ \\
\hline Miscarriage & $28-35 \%$ \\
\hline Pre-Term Delivery & $14-23 \%$ \\
\hline Live Birth & $57-63 \%$ \\
\hline
\end{tabular}

Reproductive Outcome in Women with Uterine Malformations ${ }^{2}$

Women with uterine anomalies have poor reproductive outcomes and lower pregnancy rates with the spontaneous or induced with assisted reproductive techniques compared with women with normal uterus. We present a case of ruptured pregnancy in a bicornuate uterus.

CASE REPORT: A 30 year old G2P1L1 with 6 months of amenorrhea with previous normal vaginal home delivery reported to our labor ward with severe pain in abdomen and distension in a state of hypo-volemic shock. There was no history of fever, episodes of vomiting, constipation and no history of bleeding per vagina. Her previous menstrual cycles were normal and conceived spontaneously.

On general examination, patient was in shock with pulse rate 110 per minute and blood pressure 90/60 mm of Hg. There was pallor; abdomen was distended with diffuse tenderness with marked guarding and rigidity. The size of the uterus could not be appreciated correctly. On per 
vaginal examination, the cervix was closed tubular and there was no bleeding. Her hemoglobin was 6 gm. percent, blood group $\mathrm{O}+\mathrm{ve}$. Ultrasound revealed hemoperitonium. Patient was resuscitated from shock and her blood pressure was normalized with supportive treatment with fluids. Adequate blood arranged and patient was taken for emergency laparotomy. On exploration there was hemoperitonium and fetus was in the abdominal cavity. Bicornuate uterus was seen with normal sized intact left horn and right horn showing rupture at fundus and placenta lying attached posteriorly in the cavity.

The ruptured right horn was cut at the junction with the left horn and then sutured in layers. Patient was transfused with two units of blood. Patient recovered well and was discharged on Day 10. She was started on oral contraceptives and was advised to continue for one year.

DISCUSSION: Rupture uterus is a life threatening obstetric problem. Rupture in first or second trimester generally occurs in congenitally malformed uterus like unicornuate or bicornuate uterus with or without rudimentary communicating/ non- communicating horn. In our case it was communicating bicornuate uterus with rupture of right horn. Similar case has been reported by Mane et al. $^{3}$

Bicornuate uterus is an abnormality with partial non-fusion of the mullerian duct resulting in central myometrium that can extend as far down as the internal cervical opening. This malformation makes up approximately $3 \%$ of the uterine malformations. ${ }^{3}$

The malformation in itself is asymptomatic but is associated with increased rate of reproductive problems including repeated late abortions or miscarriages.

The gold standard diagnostic tool is combination of laparoscopy and hysteroscopy, but MRI and 3D Ultrasound are considered comparable to laparoscopy/ hysteroscopy as less invasive alternatives but still with high sensitivity. ${ }^{4}$

Cornual pregnancy is pregnancy implanted in the upper lateral portion of a bicornuate or septate uterus. ${ }^{5}$

In literature, cornual pregnancy is used interchangeably with annular and interstitial pregnancy.6,7 Annular pregnancy is an intra-uterine pregnancy with a gestation implanted in the uterine cavity medial to the utero-tubal angle and round ligament. Though it is actually an intrauterine pregnancy, annular pregnancy is potentially dangerous condition associated with uterine rupture often in the second trimester. The clinical course of annular pregnancy is very variable with some full term pregnancies and spontaneous miscarriages. ${ }^{6}$

Interstitial pregnancy is an ectopic pregnancy implanted intra-murally in the proximal part of the fallopian tube lateral to the round ligament. This ectopic pregnancy typically presents and ruptures before gestation week 12 much like the more common tubal ectopic pregnancy. It is associated with higher mortality than tubal pregnancies as cornual pregnancy is difficult to diagnose pre-operatively and is easily confused with tubal ectopic pregnancy or the normal intra-uterine pregnancy. It is more difficult to differentiate between annular and interstitial pregnancy. The preoperative diagnosis of cornual pregnancy is below $70 \%$ and more often it is an intra-operative diagnosis.

CONCLUSION: Uterine abnormalities, though rare can be encountered in pregnancy. Management of cornual pregnancy depends on many factors including gestational age, hemodynamic status, presence 
of uterine rupture and the patient's wish for retaining future fertility. ${ }^{5}$ There is need to build capacity for making an antenatal diagnosis in or to ensure appropriate management

\section{REFERENCES:}

1. Harger JH, Archer DF, Marchese SG, Muracca-Clemens M, Garver KL (1983) Etiology of recurrent pregnancy losses and outcome of subsequent pregnancies. Obstet Gynecol 62: 574581.

2. Heinonen PK, Saarikoski S, Pystynen P. Reproductive performance of women with uterine anomalies: an evaluation of 182 cases. Acta Obstet Gynecol Scand 1982; 61:157-162.

3. Mane $S$, Chaudhry R, Nandanwar Y. An unusual presentation of pregnancy in bicornuate uterus. Journal of Obstetrics \& Gynecology, India 1994; 44-1, 154-155.

4. A. Ludwin, I. Ludwin, T. Banas, A. Knafel, M. Miedzyblocki and A. Basta. Diagnostic accuracy of sonohysterography, hysterosalpingography and diagnostic hysteroscopy in diagnosis of arcuate, septate and bicornuate uterus. Journal of Obstetrics and Gynecology Research, vol. 37, no. 3, pp. 178-186, 2011.

5. A. Malinowski and S. K. Bates. Semantics and pitfalls in the diagnosis of cornual/ interstitial pregnancy. Fertility and Sterility, vol. 86, no. 6, pp. 1764-e11-1764-e14, 2006.

6. L. Woh, P. R. Koh, C. N. Wong, Y. L. Sun, E. T. Lin and M. H. Huang. Laparoscopic management of a large viable cornual pregnancy. JSLS: Journal of the Society of Laparoendoscopic Surgeons, vol. 11, no. 4, pp. 506-508, 2007.

7. N. S. Moawad, S. T. Mahajan, M. H. Moniz, S. E. Taylor and W. W. Hurd. Current diagnosis and treatment of interstitial pregnancy. American Journal of Obstetrics and Gynecology, vol. 202, no. 1, pp. 15-29, 2010.

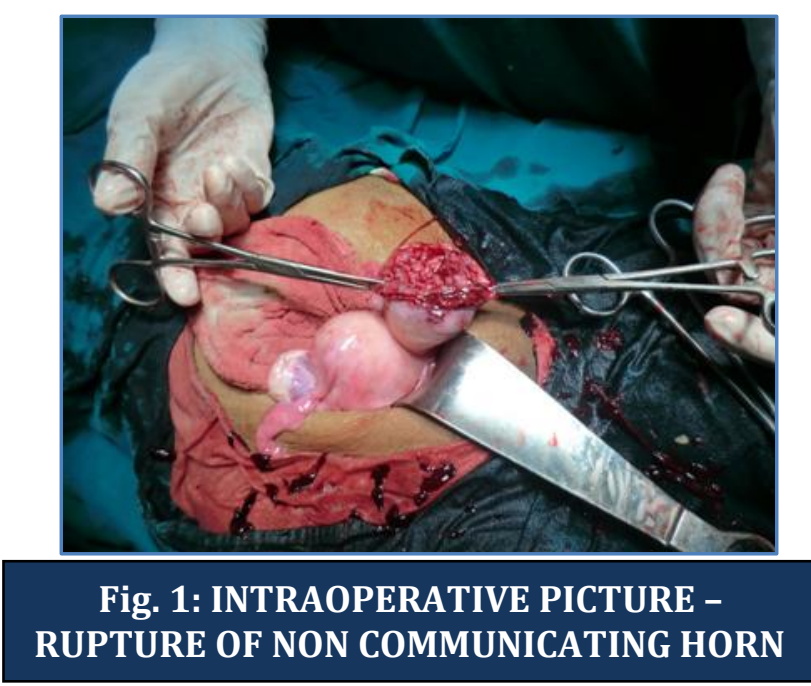




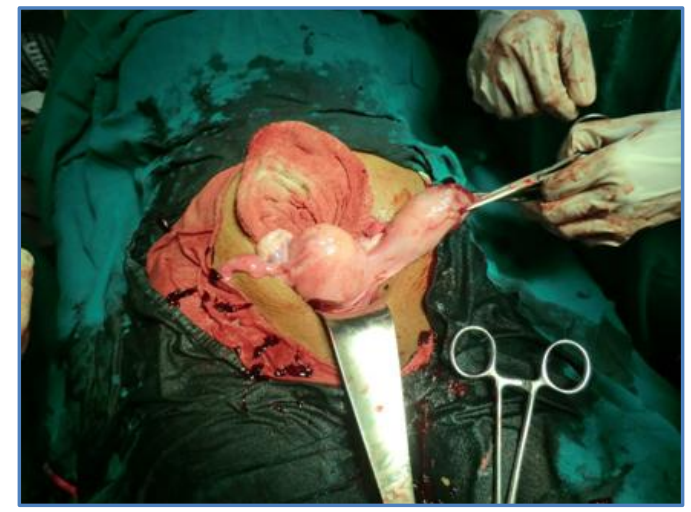

\section{Fig. 2: INTRAOPERATIVE PICTURE - SHOWING BOTH THE HORNS}

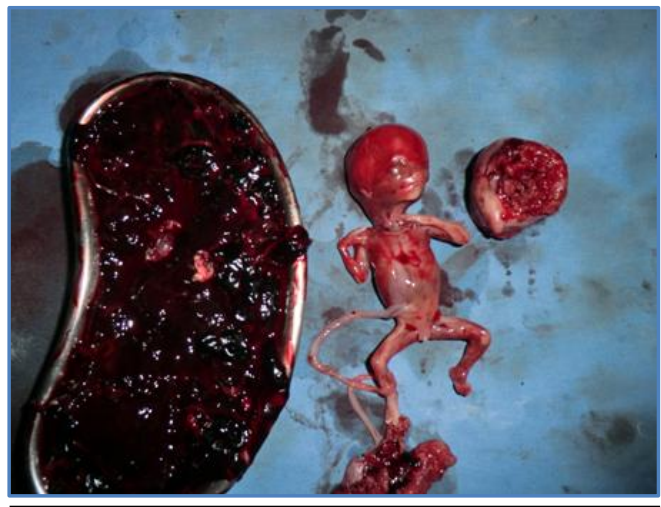

Fig. 3: HEMOPERITONIUM, FETUS, EXCISED RUPTURED HORN

\section{AUTHORS:}

1. Vijayalakshmi B.

2. Chandana $\mathrm{N}$.

\section{PARTICULARS OF CONTRIBUTORS:}

1. Associate Professor, Department of Obstetrics and Gynaecology, Vijayanagar Institute of Medical Sciences, Bellary.

2. Senior Resident, Department of Obstetrics and Gynaecology, Vijayanagar Institute of Medical Sciences, Bellary.

\section{NAME ADDRESS EMAIL ID OF THE} CORRESPONDING AUTHOR:

Dr. Vijayalakshmi,

B. No - 10/2, Ward No. - 19,

Behind Government School,

Patelnagar, Bellary - 583104.

E-mail: vijaya.b.yadav72@gmail.com aralichandana@gmail.com

Date of Submission: 17/01/2014.

Date of Peer Review: 18/01/2014.

Date of Acceptance: 03/02/2014.

Date of Publishing: 13/02/2014. 